\title{
Bulanık Veri Zarflama Analizi İle OECD Ülkelerinin Sağlık Alanındaki Etkinliklerinin Değerlendirilmesi ${ }^{1}$
}

Gözde YEŞILAAYDIN, Department of Health Management, Faculty of Health Sciences, Eskisehir Osmangazi

University, Turkey; e-mail: gterekli@gmail.com

Nesrin ALPTEKIN, Department of Business Administration, Faculty of Business Administration, Anadolu

University, Turkey; e-mail: nesrinesen@anadolu.edu.tr

\section{Evaluation of Health Efficiencies of OECD Countries by Using Fuzzy Data Envelopment Analysis ${ }^{2}$}

\begin{abstract}
This study aims to determine health efficiencies of OECD countries by using fuzzy data envelopment analysis. For evaluation of efficiencies related to the countries, input variables that directly affect the health, environment variables and output variables are used. In the fuzzy data envelopment analysis, Wang, Greatbanks and Yang (2005)'s model is used. Solutions are conducted by forming interval data in the direction of Zimmermann (1991)'s $\alpha$ - cut level approach. With fuzzy data envelopment analysis, upper and lower efficiency limits are obtained using five different $\alpha$ - cut level. For each $\alpha$-cut level, maximum loss of efficiency value of decision making units are calculated by Minimax Regret Approach and countries with inefficient scores are listed from best to the worst. Accordingly, the best loss of efficiency value belongs to Austria and the worst value belongs to Hungary for $0 ; 0,25 ; 0,50 ; 0,75 \alpha$ - cut level. Turkey is located in the middle row (rows 21 and 23) among the 34 countries for $0 ; 0,25 ; 0,50 ; 0,75 \alpha$ - cut level and it is among the efficient countries for $\alpha=1$ cut level.
\end{abstract}

Keywords $\quad$ : Efficiency, Fuzzy Data Envelopment Analysis, OECD, Health Indicators.

JEL Classification Codes : $\quad$ C6, C18, I10, I15.

1 Bu çalışma Prof.Dr. Nesrin ALPTEKIN'in danışmanlı̆̆ında, Gözde YEŞiLAYDIN'ın 2015 yılında tamamlanan "OECD Ülkelerinin Sağllk Alanındaki Etkinliklerinin Bulanık Veri Zarflama Analizi ile Belirlenmesi” başlıklı doktora tez çalışmasından üretilmiştir. Ayrıca bu tez çalışması 1503E125 numaralı proje kapsamında Anadolu Üniversitesi Bilimsel Araştırma Projeleri Komisyonunca desteklenmiştir.

2 This study is derived from Gözde YEŞILAYDIN's PhD thesis titled as "Determining of Health Efficiencies of OECD Countries by Using Fuzzy Data Envelopment Analysis" which was completed in 2015 and supervised by Prof.Dr. Nesrin ALPTEKIN and this thesis was also supported by Anadolu University Scientific Research Projects Commission within the scope of 1503 E125 numbered project. 
Yeşilaydın, G. \& N. Alptekin (2016), "Bulanık Veri Zarflama Analizi İle OECD Ülkelerinin

Sağlık Alanındaki Etkinliklerinin Değerlendirilmesi”, Sosyoekonomi, Vol. 24(30), 207-224.

\section{$\ddot{O} z$}

$\mathrm{Bu}$ çalışma, OECD ülkelerinin sağlık alanındaki etkinliklerinin bulanık veri zarflama analizi ile belirlenmesi amacıyla yapılmıştır. Ülkelere ilişkin sağlık etkinliklerinin değerlendirilmesinde sağlığı doğrudan etkileyen girdi değişkenleri, çevre değişkenleri ve çıktı değişkenleri kullanılmıştır. Bulanık veri zarflama analizinde Wang, Greatbanks ve Yang (2005)'ın önermiș olduğu model kullanılmıș ve çözümler Zimmermann (1991)'nın $\alpha$-kesim düzeyi yaklașımı doğrultusunda aralık veriler oluşturularak yapılmıştır. Bulanık veri zarflama analizi ile beş farklı $\alpha$-kesim düzeyinde alt ve üst sınır etkinlik değerleri elde edilmiştir. Her $\alpha$ kesim düzeyi için karar verme birimlerinin maksimum etkinlik kaybı değerleri Minimaks Pişmanlık Yaklaşımı ile hesaplanmış ve etkin olmayan ülkeler en iyiden en kötüye doğru sıralanmıştır. Buna göre, $\alpha=0 ; 0,25 ; 0,50$ ve 0,75 kesim düzeyinde en iyi etkinlik kaybı değeri Avusturya'ya; en kötü etkinlik kaybı değeri ise Macaristan'a aittir. Türkiye ise $\alpha$ $=0 ; 0,25 ; 0,50$ ve 0,75 kesim düzeyi için 34 ülke içerisinde orta sıralarda (21. ve 23. sıra) yer almakta; $\alpha=1$ kesim düzeyinde ise etkin ülkeler arasında bulunmaktadır.

Anahtar Sözcükler $\quad$ : Etkinlik, Bulanık Veri Zarflama Analizi, OECD, Sağlık Göstergeleri.

\section{Giriş}

Toplumların gelişmişlik göstergelerinden biri olan sağlık ve sağlığın korunması ve geliştirilmesi amacıyla sunulan sağlık hizmetleri tüm ülkeler için önem arz etmektedir. Özellikle teknolojide yaşanan hızlı değişimler, bireylerin eğitim seviyesinin ve bilinç düzeyinin yükselmesi ve sağlığa olan talebin artmasıyla birlikte sağlık hizmeti maliyetlerinde meydana gelen artışlar ülkelerin sağlığa daha fazla önem vermeleri ve sağllk etkinliklerini değerlendirmeleri gerekliliğini gündeme getirmiştir. Bu amaçla her ülkenin kendi sağlık etkinliğini belirlemesinin yanı sıra, ülkeler arası karşılaştırmalar da yapması gereklidir. Sağlık sistemlerinin etkin bir şekilde işletilmesi ve yönetilmesinde diğer ülkelerin deneyimlerinin öğrenilmesi ülkelere önemli bir firsat sunmaktadır (Kumar \& Özdamar, 2004: 83).

Günümüzde birçok ülkede birey ve toplum hayatında önemli bir yere sahip olan sağlık hizmetlerine ilişkin kaynak kıtlığı yaşanmakta, modern tıp uygulamaları sonucu yapılan harcamalar ve sağlık giderleri sürekli artmakta, sağlık hizmetleri maliyeti her zaman gündemde olmakta ve kaliteli sağlık hizmeti sunumu zorunlu hale gelmektedir (Kocaman vd., 2012: 16; Temür \& Bakırc1, 2008: 265). Sağlık hizmetlerine erişimde bireylerin beklentilerinin, eğitim ve gelir seviyesinin artması ancak bütçenin kısıtlı olması nedeniyle mevcut kaynaklarla toplumun sağlık düzeyinin yükseltilmesi gerekliliği sağlık sistemi ve karar vericiler üzerinde baskı oluşturmaktadır (Tarcan vd., 2015: 99). Dolayısıyla büyük yatırımların yapıldığı sağlık sektörü için kaynakların etkin kullanımı hayati önem taşımaktadır (Kocaman vd., 2012: 15). Bu amaçla sağlık yöneticileri ve politika yapıcılar mevcut kaynakları olabildiğince verimli, etkin ve optimal bir şekilde kullanarak maksimum toplum refahı elde etmeye çalışmaktadırlar (Demir \& Bakırc1, 2014: 115).

Ülkelerin sağlık düzeylerinin incelenerek gelişmişlikleri hakkında bilgi elde edilmesi ve ülkelerarası karşılaştırmalar yapılabilmesi için objektif, standart ve niceliksel birtakım göstergelere ihtiyaç duyulmaktadır. Bu göstergeler literatürde "sağlık göstergeleri" olarak adlandırılmaktadır (Altıntaş, 2012: 23). Sağlık göstergeleri, temel sağlık hizmetlerine ilişkin 
politikaların belirlenmesi, sağlı hizmetlerinin yönetimi, planlanması ve programlanması, sağlık alanındaki talebin belirlenmesi ve karşılanması, toplumların sağlık düzeylerinin değerlendirilmesi, sağlık sorunlarının tespiti ve çözümü, toplum sağlığının farklı boyutlarının ve yaş, cinsiyet, nüfus gibi bazı faktörlere göre değişiminin ölçümü amacıyla geliştirilen ölçütlerdir (Lorcu, 2008: 192; Çilingiroğlu, 1995'ten aktaran Orhan Aksoy, 2007: 3).

Sağlık göstergeleri ile toplumların sağlık düzeyi, sorunları ve sağlık hizmetlerinin etkinliği hakkında bilgi elde edilmesinin yanı sıra, toplumun ya da belli bir kesimin sağlık durumunun belli bir zaman dilimindeki değişimlerinin ölçülmesi ve ülkeler arası karşılaştırma ve kıyaslama yapılması mümkün olmaktadır (Lorcu, 2008: 192; Sağlık Bakanlığı Temel Sağlık Hizmetleri Genel Müdürlüğü, 2011: 9; Vehid, 2000: 100-101). Sağlık göstergeleri ile yapılan karşılaştırmalar sunulan sağlık hizmetinin hangi alanda başarılı, hangi alanda başarısız olduğunun ortaya konması ve başarısız olunan kısımlarda gerekli önlemlerin alınması açısından oldukça yararlıdır (Sümbüloğlu vd., 1999: 89).

Ulusal ve uluslararası kuruluşlar, referans gruplar ve akademisyenler tarafindan geliştirilen çok sayıda sağlık göstergesi ve gösterge tanımı bulunmaktadır. Son yıllarda WHO (2014) tarafından geliştirilen “Çekirdek Sağlık Göstergeleri Küresel Referans Listesi - Global Reference List of 100 Core Health Indicators" ile sağlik göstergeleri detaylandırılmış ve her bir göstergeye ilişkin alt boyutlar tanımlanmıştır. Bu listede "sağlık durumu göstergeleri" ana başlı̆̆ı altında mortalite, morbidite ve doğurganlık; "risk faktörleri” başlığ 1 altında beslenme, enfeksiyonlar, çevresel risk faktörleri, bulaşıcı olmayan hastalıklar ve yaralanmalar; "sağlık hizmeti kapsamı" başlığı altında üreme, anne, yeni doğan, çocuk ve ergenlere ilişkin göstergeler, aşılama, HIV, tüberküloz, sıtma, tarama ve önleyici bakım, akıl sağlı̆̆ı; "sağlık sistemleri" başlı̆̆ı altında ise bakım kalitesi ve güvenliği, erişim, sağlık insangücü, sağlık bilgisi, sağlık finansmanı ve sağlık güvenliği gibi alt başlıklar bulunmaktadır.

$\mathrm{Bu}$ çalışmada uluslararası literatürde kabul görmüş sağlık göstergeleri kullanılarak Türkiye'nin de içinde bulunduğu OECD ülkelerinin sağlık alanındaki etkinliklerinin bulanık veri zarflama analizi ile belirlenmesi amaçlanmıştır.

\section{Bulanık Veri Zarflama Analizi}

Gerçek hayatta karşılaşılan olayların ya da durumların birçoğu çeşitli açılardan belirsiz olabilir. Bilgi eksikliği nedeniyle bir sistemin mevcut durumu net bir şekilde bilinemeyebilir veya ifade edilemeyebilir. Özellikle etkinlik ölçümünde girdi ve çıtı değişkenlerine ilişkin verilerin tam ve doğru olarak elde edilmesi oldukça güçtür, hatta çoğu durumda belirsizlikler içermekte ya da düzgün veri elde edilmesi mümkün olamamaktadır (Artut, 2013: 34; Güngör \& Oruç, 2009: 18). Belirsizlik nedeniyle kesin olmayan verilerle de karşılaşılmaktadır (Hatami- Marbini vd., 2011: 457; Hatami- Marbini, 2011: 40; Razavi vd., 2013: 595). Sağlık hizmeti sunumu ile ilgili etkinliklerin değerlendirilmesinde kullanılan sağlık göstergelerine ilişkin istatistiklerin tutulmasında da eksik ya da yanlış verilerle karşılaşılması söz konusu olabilmektedir. 
Yeşilaydın, G. \& N. Alptekin (2016), "Bulanık Veri Zarflama Analizi İle OECD Ülkelerinin

Sağlık Alanındaki Etkinliklerinin Değerlendirilmesi”, Sosyoekonomi, Vol. 24(30), 207-224.

Verilerin kalitatif olduğu ya da kesin olarak bilinmediği, verilerde eksiklik, yanlışlık ya da belirsizlik olduğu durumlarda etkinlik ölçümlerinin yapılabilmesi için bulanık küme teorisinden ve üyelik fonksiyonlarından yararlanılarak oluşturulan Bulanık Veri Zarflama Analizi (BVZA) modelleri geliştirilmiştir (Artut, 2013: 34; Oruç vd., 2009: 280).

Bulanık Veri Zarflama Analizi, bulanık gözlemler içeren karar verme birimleri için bulanık etkinlik ölçümleri yapabilen bir yöntemdir (Ege, 2009). Bulanık veriler kullanan BVZA, gerçek hayattaki durumları, klasik veri zarflama analizine göre daha gerçekçi bir şekilde ifade etmektedir (Lertworasirikul vd., 2003: 339). Bazı veriler bulanık olduğunda, karar sürecindeki amaç ve kısıtlar da bulanık hale gelmektedir. Dolayısıyla BVZA problemlerine bulanık doğrusal programlama tekniklerinin uygulanması gerekmektedir (Kahraman \& Tolga, 1998'den aktaran Güneş, 2006: 48).

Bulanık veri zarflama analizi ile ilgili etkinlik ölçümüne ilişkin geliştirilmiş çeşitli bulanık veri zarflama analizi modelleri bulunmaktadır. Bu çalışmada Wang, Greatbanks ve Yang (2005) Modeli kullanılmıştır. Bu model diğer modellere göre ekstra değişken dönüşümlerine gerek duymamakta aynı zamanda bulanık verileri diğer modellere göre daha basit ve etkin bir biçimde modellemektedir. Ayrıca modelin literatürde sıklıkla yer alması ve modeli kullanan çok sayıda tez ve makalenin bulunması da bu modelin kullanılmasında etkili olan nedenlerdendir. Örneğin, Apaydın ve Güneş (2007), Türkiye'de birinci derece kalkınma öncelikli yörelerin ve Şafak vd. (2013) İzmir Orman Bölge Müdürlüğü’ne bağlı bucaklardaki orman işletmelerinin etkinliklerinin değerlendirilmesinde bu modeli kullanmışlardır. Ayrıca Hadi-Vencheh vd. (2014), aralık verilerden oluşan beş girdi ve iki çıktı değişkeni ile yirmi beş karar verme biriminin etkinliğini değerlendirdikleri çalışmada, göreli etkinlik ölçümünde alternatif bir model önermişler ve önerilen bu modelde Wang Greatbanks ve Yang (2005) tarafindan oluşturulan alt sınır ve üst sınıra ilişkin matematiksel modelden yararlanmışlardır. Benzer şekilde Saen (2011: 599) de uluslararası pazar (ülke) seçimi ile ilgili yapmış olduğu çalışmasında kesin olmayan veriler ile ilgili geliştirilen bir model önermiştir. Önerilen bu modelde de Wang Greatbanks ve Yang (2005) modelinden yararlanılmıştır. Modeli kullanan tezlere bakıldığında Şafak (2009)'ın, Ege Bölgesi orman işletmelerinin etkinlik düzeylerinin belirlenmesi ile ilgili doktora tez çalışmasında; Balkan (2011)'ın, 45 ülkenin hisse senedi piyasalarının etkinliğini değerlendirdiği yüksek lisans tez çalışmasında ve Çakır (2015)'ın, Borsa İstanbul'a kote olmuş ve teknoloji/bilişim sektöründe faaliyet gösteren on altı firmanın etkinliğini değerlendirdiği doktora tez çalışmasında bu modelin kullanıldığı görülmektedir.

\subsection{Wang, Greatbanks ve Yang (2005) Modeli}

Bu model, aralık girdi ve çıktı değişkenleri kullanılarak her bir karar verme biriminin göreli etkinliğinin alt ve üst sınırını ölçmek için geliştirilmiştir (Wang vd., 2005a). Modelde, "karar verme birimi”, KVB şeklinde kısaltılmıştır.

$\mathrm{KVB}_{j}$ 'nin etkinliği, 


$$
\theta_{\mathrm{j}}=\frac{\sum_{r=1}^{s} u_{r} y_{r j}}{\sum_{i=1}^{m} v_{i} x_{i j}}, \quad \mathrm{j}=1, \ldots, \mathrm{n}
$$

şeklinde belirtilebilir. Aralık verilere ilişkin işlemlerde kullanılan kurallara göre $\mathrm{KVB}_{j}$ 'nin etkinliği aşağıdaki gibi olmaktadır.

$$
\theta_{\mathrm{j}}=\frac{\left.\sum_{r=1}^{s} u_{r}\left[y_{r j}{ }^{\mathrm{L}}, y_{r j}{ }^{\mathrm{U}}\right]\right]}{\sum_{i=1}^{m} v_{i}\left[x_{i j}{ }^{\mathrm{L}}, x_{i j}{ }^{\mathrm{U}}\right]}=\frac{\left[\sum_{r=1}^{s} u_{r} y_{r j}{ }^{\mathrm{L}}, \sum_{r=1}^{s} u_{r} y_{r j}{ }^{\mathrm{U}}\right]}{\left[\sum_{i=1}^{m} v_{i j} x^{\mathrm{L}}, \sum_{i=1}^{m} v_{i} x_{i j}^{\mathrm{U}}\right]}=\left[\frac{\left[\sum_{r=1}^{s} u_{r} y_{r j}{ }^{\mathrm{L}}, \sum_{r=1}^{s} u_{r} y_{r j}{ }^{\mathrm{U}}\right]}{\left[\sum_{i=1}^{m} v_{i} x_{i j}{ }^{\mathrm{U}}, \sum_{i=1}^{m} v_{i} x_{i j}{ }^{\mathrm{L}}\right]}\right],
$$

$\mathrm{j}=1, \ldots \mathrm{n}$

Burada $\theta_{\mathrm{j}}$, bir aralık sayı olarak $\left[\theta_{j}^{\mathrm{L}}, \theta_{j}^{\mathrm{U}}\right](\mathrm{j}=1, \ldots, \mathrm{n})$ şeklinde gösterilmektedir.

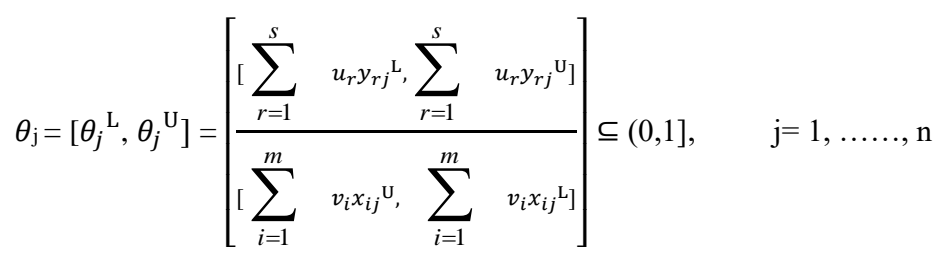

Buradan,

$$
\begin{aligned}
\theta_{j}^{\mathrm{U}} & =\frac{\sum_{r=1}^{s} u_{r} y_{r j}^{\mathrm{U}}}{\sum_{i=1}^{m} v_{i} x_{i j}^{\mathrm{L}}} \leq 1, \quad \mathrm{j}=1, \ldots, \mathrm{n} \\
\theta_{j}{ }^{\mathrm{L}} & =\frac{\sum_{r=1}^{s} u_{r} y_{r j}{ }^{\mathrm{L}}}{\sum_{i=1}^{m} v_{i} x_{i j} \mathrm{U}} 0, \quad \mathrm{j}=1, \ldots ., \mathrm{n}
\end{aligned}
$$


olarak ifade edilebilir.

$\mathrm{KVB}_{0}$ ’ın alt ve üst sınırlarının etkinliğini ölçmek için geliştirilen doğrusal programlama modeli aşağıdaki gibidir.

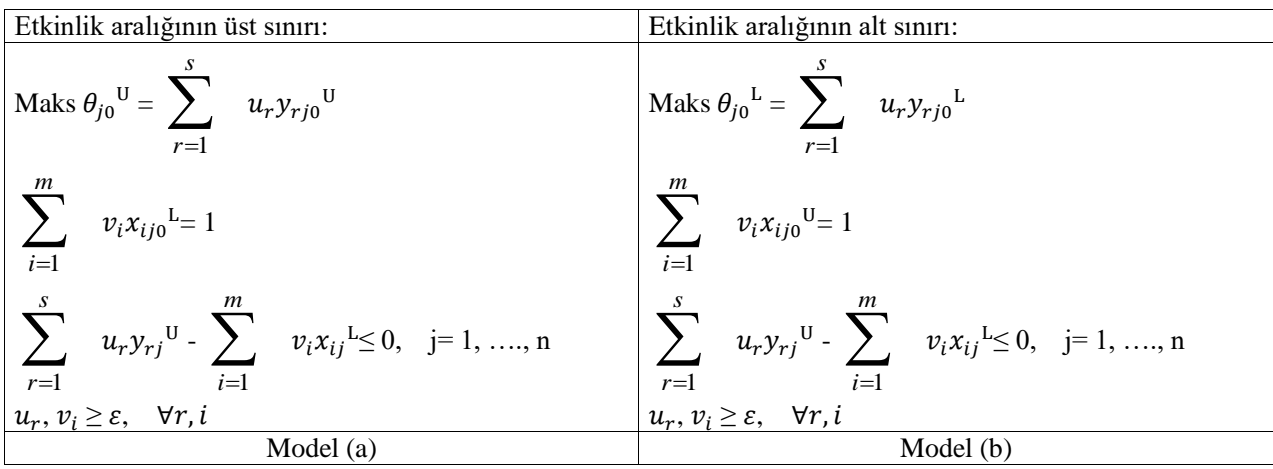

Model (a)'da yer alan $\theta_{j 0} \mathrm{U}$, tüm KVB'ler en iyi üretim etkinliği durumunda iken, $\mathrm{KVB}_{0}$ aracılığıyla elde edilen en iyi olası göreli etkinliği ifade etmektedir. Model (b)'de yer alan $\theta_{j 0}{ }^{\mathrm{L}}$ ise; $\mathrm{KVB}_{0}$ en iyi olası göreli etkinliğinin alt sınırını temsil etmektedir. Dolayısıyla $\left[\theta_{j 0}^{\mathrm{L}}, \theta_{j 0}^{\mathrm{U}}\right]$, olası en iyi göreli etkinlik aralığını oluşturmaktadır.

\subsection{Minimaks Pişmanlık Yaklaşımı}

Her bir karar verme biriminin etkinlik değeri bir aralık ile tanımlanmaktadır. Aralık değerlerin genişlikleri farklı olmasına rağmen merkezleri aynı olduğunda, karar verme birimlerine ait etkinlik değerleri doğrudan karşılaştırılamayabilir. Bu durumda etkinlik değerlerinin sıralanması ve karşılaştırılmasında kullanılacak bir tekniğe ihtiyaç duyulmaktadır (Wang vd., 2005a: 361). Bu ihtiyaçtan yola çıkarak Wang vd. (2005b), geliştirmiş oldukları aralıklı veri zarflama analizi modeline ek olarak, karar verme birimlerinin etkinliklerinin sıralandığ 1 ve karşılaştırıldığı yeni bir yaklaşım "Minimaks Pişmanlık Yaklaşımı - Minimax Regret-BasedApproach” önermişlerdir. Bu yaklaşım, Wang vd. (2005a) tarafindan detaylı olarak anlatılmış olup; yaklaşıma ilişkin bilgiler aşağıda sunulmuştur.

$$
\mathrm{A}_{\mathrm{i}}=\left[a_{i}{ }^{\mathrm{L}}, a_{i}^{\mathrm{U}}\right]=\left\langle m\left(A_{i}\right), \mathrm{w}\left(A_{i}\right)\right\rangle(\mathrm{i}=1, \ldots, \mathrm{n}) \mathrm{n} \text { adet KVB' nin etkinlik aralığ }
$$
olsun. Burada $\mathrm{m}\left(\mathrm{A}_{\mathrm{i}}\right)=\frac{1}{2}\left(a_{i}{ }^{\mathrm{R}}+a_{i}{ }^{\mathrm{L}}\right) \mathrm{KVB}$ 'lerin orta noktasını yani merkezini; $\mathrm{w}\left(\mathrm{A}_{\mathrm{i}}\right)=\frac{1}{2}\left(a_{i}{ }^{\mathrm{R}}\right.$ - $\left.a_{i}{ }^{\mathrm{L}}\right)$ ise genişliğini göstermektedir. $\mathrm{A}_{\mathrm{i}}=\left[a_{i}{ }^{\mathrm{L}}, a_{i}{ }^{\mathrm{U}}\right]$ ifadesinin en iyi etkinlik aralığını temsil ettiği varsayıldığında, $\mathrm{b}=\operatorname{maks}_{j \neq i}\left\{a_{j}{ }^{\mathrm{U}}\right\}$ olsun. Eğer $a_{i}{ }^{\mathrm{L}}<\mathrm{b}$ olursa, karar vericiler için etkinlik kaybı (diğer ismiyle firsat ya da pişmanlık kaybı) oluşur ve karar verici pişman olur. Maksimum etkinlik kaybı maks $\left(\mathrm{r}_{\mathrm{i}}\right)=\mathrm{b}-a_{i}^{\mathrm{L}}=\operatorname{maks}_{j \neq i}\left\{a_{j}^{\mathrm{U}}\right\}-a_{i}{ }^{\mathrm{L}}$ şeklinde ifade edilir. 
Eğer $a_{i}{ }^{\mathrm{L}} \geq \mathrm{b}$ ise, karar vericiler için etkinlik kaybı ve pişmanlık oluşmaz. Bu durumda pişmanlık sıfır olarak $\left(r_{i}=0\right)$ tanımlanır. Yukarıda açıklanan iki durum birleştirildiğinde;

$$
\operatorname{maks}\left(\mathrm{r}_{\mathrm{i}}\right)=\operatorname{maks}\left[\operatorname{maks}_{j \neq i}\left(a_{j}^{\mathrm{U}}\right)-a_{i}^{\mathrm{L}}, 0\right]
$$

oluşur. Böylece, minimaks pişmanlık kriteri, izleyen koşulları sağlayan etkinlik aralığı olarak seçilir.

$$
\begin{aligned}
& \min _{i}\left\{\operatorname{maks}_{(\mathrm{i})}\right)=\min _{i}\left\{\operatorname{maks}\left[\operatorname{maks}_{j \neq i}\left(a_{j}{ }^{\mathrm{U}}\right)-a_{i}{ }^{\mathrm{L}}, 0\right]\right\} \\
& \mathrm{A}_{\mathrm{i}}=\left[a_{i}{ }^{\mathrm{L}}, a_{i}^{\mathrm{U}}\right]=\left\langle m\left(A_{i}\right), \mathrm{w}\left(A_{i}\right)\right\rangle \quad(\mathrm{i}=1, \ldots, \ldots, \mathrm{n}) \text { etkinlik aralıkları kümesi olsun. }
\end{aligned}
$$

Her etkinlik aralığ $A_{i}$ 'nin maksimum etkinlik kaybı (maksimum pişmanlık);

$$
\begin{aligned}
& \mathrm{R}\left(\mathrm{A}_{\mathrm{i}}\right)=\operatorname{maks}\left[\operatorname{maks}_{j \neq i}\left(a_{j}{ }^{\mathrm{U}}\right)-a_{i}{ }^{\mathrm{L}}, 0\right]=\operatorname{maks}\left[\operatorname{maks}_{j \neq i}\left\{m\left(A_{j}\right)+w\left(A_{j}\right)\right\}-\left(m\left(A_{i}\right)-\right.\right. \\
& \left.\left.w\left(A_{i}\right)\right), 0\right], \mathrm{i}=1, \ldots . ., \mathrm{n}
\end{aligned}
$$

şeklinde tanımlanır. Bu durumda maksimum etkinlik kaybı en düşük olan etkinlik aralığı, en çok tercih edilen, en cazip etkinlik aralığıdır.

\section{Sağlık Sektöründe Bulanık Veri Zarflama Analizinin Kullanımı}

Bulanık veri zarflama analizinin üretim işletmelerinin, sigorta şirketlerinin, orman işletmelerinin, bankaların, tedarikçilerin, illerin, ülkelerin, fakültelerin veya üniversitelerin etkinliğinin belirlenmesinde kullanıldığı çok sayıda çalışma mevcuttur. Bulanık veri zarflama analizi kullanılarak sağlık alanında yapılan çalışmalara bakıldığında ise sayının çok fazla olmadığı söylenebilir. Bulanık veri zarflama analizinin sağlık alanında kullanıldığı çalışmalara ilişkin bilgiler aşağıda sunulmuştur:

- Afsharinia vd. (2013) tarafından yapılan çalışmada, klinik birimlerin belirsizlik altında performans ölçümünün bağımsız bileşen analizi ve bulanık veri zarflama analizi yaklaşımlarının entegrasyonu ile değerlendirilmesi amaçlanmıştır. Çalışmada yatak sayısı, hekim ve hemşire sayısı, ekipman maliyeti, yardımcı personel sayısı girdi değişkenleri; yatan hasta ziyaret sayısı ve yatak doluluk oranı ise çıktı değişkenleri olarak kullanılmıştır. Çalışma sonucunda bulanık koşullar altında, bulanık veri zarflama analizi kullanılarak toplam on dokuz karar verme biriminden on ikisi etkin birim olarak elde edilirken; bağımsız bileşen analizi ve bulanık veri zarflama analizinin birlikte kullanılması ile sadece üç karar verme birimi etkin birim olarak belirlenmiştir. Sonuç olarak, doğru verilere erişim sınırlı olduğunda klinik birimlerin etkinliğinin tahmin edilmesi için bağımsız bileşen analizi-bulanık veri zarflama analizinin kullanılması tavsiye edilmektedir.

- Costantino vd. (2013), belirsizlik altında sağlık sistemlerinin performansının değerlendirilmesine ilişkin sorunu çözmek amacıyla çapraz etkinlik bulanık veri zarflama analizi (cross-efficiency fuzzy data envelopment analysis) yönteminin kullanılabileceğini belirtmiştir. Çalışmada bu yöntem ile Güney İtalya'daki bölge hastanelerinin etkinlikleri değerlendirilmiş; sağlık reformlarının planlanması ve 
Yeşilaydın, G. \& N. Alptekin (2016), "Bulanık Veri Zarflama Analizi İle OECD Ülkelerinin

Sağlık Alanındaki Etkinliklerinin Değerlendirilmesi”, Sosyoekonomi, Vol. 24(30), 207-224.

değerlendirilmesinde uygulama kolaylı̆ğ sunan bir hastanenin performansının zamansal evrimi tahmin edilmiştir. Çalışmada on beş karar verme birimi ele alınmış; girdi ve çıktı değişkenleri için üçgen bulanık sayılar kullanılmıştır. Hekim sayısı, hemşire sayısı, yatak sayısı ve diğer çalışanlar ve idari personel sayısı girdi değişkenleri; taburcu sayısı, yatılan gün sayısı ve ameliyat sayıları da çıktı değişkenleri olarak belirlenmiştir. Önerilen bu yöntemin kamu ve özel hastanelerin performanslarının karşılaştırılmalı olarak değerlendirilmesinde kullanılabileceği belirtilmiştir.

- Ebrahimnejad (2012) tarafindan yapılan çalışmada veri zarflama analizi kullanılarak karar verme birimlerinin maliyet etkinliğinin belirlenmesinde girdi fiyatları yamuk bulanık sayı olarak belirtilmiş; bu sayede maliyet etkinliğinin hesaplanmasında yeni bir yaklaşım önerilmiş̧ir. Çalışmada iki farklı örnek uygulama geliştirilmiş; bu örneklerden birinde ise hastane veri seti kullanılmıştır. Hekim ve hemşire sayısı girdi değişkeni; ayaktan hasta ve yatan hasta sayısı ise çıktı değişkeni olarak ele alınmış; her hastane için hekim ve hemşirelerin bulanık göreli birim maliyetleri yamuk bulanık sayı olarak belirlenmiştir.

\section{Yöntem}

\subsection{Araştırmanın Amacı, Özgünlüğü ve Önemi}

$\mathrm{Bu}$ çalışmada, uluslararası literatürde kabul görmüş sağlık göstergeleri kullanılarak Türkiye'nin de içinde bulunduğu OECD'ye üye ülkelerin sağlık etkinliklerini bulanık veri zarflama analizi ile değerlendirmek; ülkelerin etkinlik kaybı değerlerini hesaplamak ve etkin olmayan ülkeleri en iyiden en kötüye doğru sıralamak ve ülkeler arası karşılaştırmalar yapmak amaçlanmıştır.

Yabancı literatürde bulanık veri zarflama analizi ile ilgili yapılmış çalışmalar bulunmakla birlikte, bu çalışmaların genellikle hastane gibi sağlık kurumu düzeyinde yapıldığı söylenebilir. Yapılan literatür taramasında bulanık veri zarflama analizi kullanarak sağlıkla ilgili ülke karşılaştırmaları yapan herhangi bir çalışmaya ulaşılamamıştır. Ayrıca bulanık veri zarflama analizinin sağlı alanındaki kullanımına ilişkin Türkçe olarak yayınlanmış herhangi bir çalışmaya da rastlanılmamıştır. $\mathrm{Bu}$ durumun, bu çalışmanın özgünlüğünü ortaya koyduğu düşünülmektedir.

Çalışmada ayrıca doğrudan sağlık ile ilgili girdilere ek olarak, sağlığı dolaylı etkilediği düşünülen çevre değişkenlerine de yer verilmiştir. Çevre değişkenlerinin de kullanılması ile ülkelerin sağlık etkinliklerinin daha kapsamlı olarak incelenecek olması araştırmanın önemini ortaya koymaktadır.

\subsection{Karar Verme Birimlerinin Seçilmesi}

Araştırmaya Türkiye'nin de içinde bulunduğu OECD (Ekonomik İşbirliği ve Kalkınma Örgütü - Organization for Economic Cooperation and Development), üyesi ülkeler dâhil edilmiştir. OECD'ye üye 2014 yılı itibariyle toplam 34 ülke bulunmaktadır. Dolayısıyla bu otuz dört ülke araştırmanın karar verme birimlerini oluşturmaktadır. 


\subsection{Girdi ve Çıktı Değişkenlerinin Seçilmesi}

Sağlık, kendi başına kapalı bir sistem değildir. Bir ülkenin veya toplumun sosyoekonomik, siyasal, tarihsel, sosyal, çevresel, kültürel yapısı ile eğitim, altyapı, barınma, beslenme, trafik, kent hizmetleri gibi birçok etmenle karşılıklı bir iletişim ve etkileşim halindedir (Ünal, 2012: 206). Sosyal ve çevresel koşulların sağlık üzerindeki etkileri uzun süredir araştırılmakta ve tartışılmaktadır. Auster vd. (1972: 146)'nin yapmış olduğu araştırmaya göre; ülkeler arasındaki yaşa ve cinsiyete özel ölüm oranlarının \% 50'den fazlası, tıbbi bakım hizmetleri ve çevresel faktörlerin birleşimi ile ilişkilidir. Bu nedenle ülkelerin sağlık alanındaki etkinlikleri değerlendirilirken sağlıkla doğrudan ilişkili olmayan ancak sağlığı dolaylı olarak etkilediği düşünülen bazı değişkenleri de dikkate almak gerekmektedir. Bu düşünceden yola çıkılarak bu çalışmada girdi değişkenlerine ek olarak sağlığı dolaylı etkilediği düşünülen çevre değişkenlerine de yer verilmiştir.

Çalışma kapsamında kullanılacak olan sağlığı doğrudan etkilediği düşünülen değişkenler ile sağlıkla dolaylı olarak ilişkili olan çevre değişkenleri yapılan kapsamlı literatür incelemesi sonucunda belirlenmiş ve en uygun veri seti oluşturulmaya çalışılmıştır. Değişkenlerin belirlenmesinde ayrıca Lorcu vd. (2012) tarafından yapılan çalışmada bahsi geçen Birleşmiş Milletler Binyıl Kalkınma Hedefleri kapsamında yer alan sağlık indikatörlerinden ve WHO (2014) tarafından geliştirilen "Çekirdek Sağlık Göstergeleri Küresel Referans Listesi”nden yararlanılmıştır.

Çalışmada bulanık veri zarflama analizinde etkinlik ölçümü için kullanılmak üzere seçilen girdi, çevre ve çıktı değişkenleri ve değişenlere ilişkin ortalama, standart sapma, minimum ve maksimum değerler Tablo 1'de sunulmuştur.

Tablo: 1

Bulanık Veri Zarflama Analizinde Kullanılacak Değişkenler, Değişkenlere İlişkin Ortalama, Standart Sapma, Minimum ve Maksimum Değerler

\begin{tabular}{|c|c|c|c|c|}
\hline & Ort. & S.S. & Min. & Maks. \\
\hline \multicolumn{5}{|l|}{ Girdi Değişkenleri } \\
\hline Hekim Sayısı (1000 kişiye düşen) & 3,1494 & 0,959 & 1,03 & 6,17 \\
\hline Hastane Yatağı Sayısı (1000 kişiye düşen) & 4,8043 & 2,499 & 1,57 & 13,36 \\
\hline $\begin{array}{l}\text { Kişi Başı Sağlık Harcamaları } \\
\text { (Satın Alma Gücü Paritesi, (US\$) }\end{array}$ & 3388,8824 & 1621,759 & 890,00 & 8454,00 \\
\hline \multicolumn{5}{|l|}{ Çevre Değişkenleri } \\
\hline Günlük Sigara İçen 15 Yaș Üstü Erişkin Yüzdesi (\%) & 20,6191 & 5,263 & 11,80 & 38,92 \\
\hline Meyve Tüketimi (Yllda kişi bașına kg) & 103,9824 & 34,741 & 51,10 & 201,60 \\
\hline Kızamık Aşısı Olan Çocukların Yüzdesi (\%) & 94,6471 & 4,545 & 76,00 & 99,00 \\
\hline $\begin{array}{l}\text { Karbonmonoksit (CO) Emisyonu } \\
\text { (Kişi başı kg) }\end{array}$ & 71,5477 & 62,921 & 14,27 & 296,82 \\
\hline 5-39 Yaş Arası Beklenen Okullaşma (Eğitim) Yılı (Yll) & 17,5659 & 1,286 & 14,35 & 19,79 \\
\hline \multicolumn{5}{|l|}{ Çıktı Değişkenleri } \\
\hline $\begin{array}{l}\text { Doğumda Beklenen Yaşam Süresi } \\
\text { (Yll - Toplam Popülasyon) }\end{array}$ & 80,1768 & 2,434 & 74,40 & 83,20 \\
\hline Anne Ölüm Hızı (100 000 canlı doğumda) & 6,8562 & 7,758 & 0,01 & 42,30 \\
\hline
\end{tabular}

Ort. Ortalama; S.S. Standart Sapma; Min. Minimum; Maks. Maksimum 
Bulanık veri zarflama analizinde kullanılmak üzere üç girdi, beş çevre ve iki çıktı değişkeni belirlenmiştir. Analizde çevre değişkenleri birer girdi değişkeni olarak ele alınacaktır. Dolayısıyla analizde kullanılmak üzere 8 girdi ve 2 çıktı değişkeni söz konusudur.

\subsection{Verilerin Elde Edilmesi}

Araştırmada kullanılan değişkenlere ilişkin verilerin büyük bir bölümü OECD üyesi ülkelere ilişkin çok sayıda verinin ve meta verinin bulunduğu OECD veri tabanında yer alan istatistiklerden (http://stats.oecd.org/) elde edilmiştir. Hekim sayısı ile ilgili OECD veri tabanında yer alan istatistiklere bakıldığında; hekim sayılarının toplam olarak ele alınmadı̆̆ı; farklı hekim türlerine göre (pratisyen hekim, uzman hekim, asistan hekim, öğretim üyesi hekimler, hekim olup mesleğini icra etmeyen, iş bulamayan ya da emekli olan hekimler) verilerin bulunduğu görülmektedir. Ancak bu hekim türlerinde bazı ülkelere ilişkin veriler bulunmamaktadır. Bu nedenle sadece "1000 kişiye düşen hekim sayısı" değişkenine ilişkin veriler Dünya Bankası'ndan elde edilmiştir. Verilerin bulanık veri zarflama ile analizinde NCSS 10 paket programı kullanılmıştır.

Çalışmada hem OECD hem de Dünya Bankası veri tabanlarında yer alan 2013 verilerinin bazı ülkelerde birçok değişken için eksik olduğu gözlenmiştir. Bu nedenle verilere erişimin daha yüksek olduğu 2012 verileri kullanılarak analizler yapılmıştır. Ancak bazı ülkelerde bazı değişkenler için 2012 verilerine erişilememiş; bu durumda o ülke için en yakın döneme ait veriler analize dâhil edilmiştir. Retzlaff-Roberts vd. (2004: 57)'e göre, değişkenlerin ilgili yıla ilişkin değerleri temin edilemediğinde bazı ülkeler için bazı değişkenlere ait eski değerler bir miktar kullanılabilmekte ve bu düzenleme OECD ile ilgili çalışmaların ortak bir özelliği olup, kaçınılmaz bir durum yaratmaktadır.

\section{Bulgular}

Çalışma kapsamında OECD ülkelerinin sağlık alanındaki etkinliklerinin değerlendirilmesinde öncelikle Wang vd. (2005a) tarafından önerilen bulanık veri zarflama analizi yaklaşımı kullanılmış ve her bir karar verme birimine ilişkin farklı $\alpha$ düzeyinde alt sınır ve üst sınır değerleri hesaplanarak etkinlikler belirlenmiştir. Araştırmada kullanılan $\alpha$ kesim düzeyleri $0 ; 0,25 ; 0,50 ; 0,75$ ve 1 'dir. Sonraki aşamada karar verme birimlerinin etkinliklerinin sıralanmasında Wang vd. (2005b) tarafından geliştirilen "Minimaks Pişmanlık Yaklaşımı” kullanılarak ülkeler, farklı $\alpha$ seviyeleri için etkinlik kaybı değerlerine göre sıralanmıştır.

\subsection{Alt ve Üst Sınır Etkinliklerine Yönelik Bulgular}

OECD ülkelerinin her $\alpha$ - kesim düzeyi için bulanık veri zarflama analizi kullanılarak elde edilen alt sınır etkinlik değerlerine ilişkin veriler Tablo 2'de sunulmuştur. 
Tablo: 2

Bulanık Veri Zarflama Analizi Çözümünde $\alpha$ - Kesim Düzeyleri İçin Alt Sınır Etkinlik Değerleri

\begin{tabular}{|l|c|c|c|c|c|}
\hline & \multicolumn{5}{|c|}{ ALT SINIR ETKİNLIKK DEĞERLERİ } \\
\hline & $\mathbf{\alpha = 0}$ & $\mathbf{\alpha = 0 , 2 5}$ & $\boldsymbol{\alpha}=\mathbf{0 , 5 0}$ & $\boldsymbol{\alpha}=\mathbf{0 , 7 5}$ & $\boldsymbol{\alpha}=\mathbf{1}$ \\
\hline ABD & 0,9528 & 0,9642 & 0,9762 & 0,9880 & 1,0000 \\
\hline Almanya & 0,8901 & 0,9019 & 0,9140 & 0,9290 & 0,9466 \\
\hline Avustralya & 0,9425 & 0,9561 & 0,9705 & 0,9852 & 1,0000 \\
\hline Avusturya & 0,9696 & 0,9773 & 0,9847 & 0,9926 & 1,0000 \\
\hline Belçika & 0,9332 & 0,9496 & 0,9660 & 0,9829 & 1,0000 \\
\hline Birleşik Kralık & 0,9588 & 0,9689 & 0,9793 & 0,9894 & 1,0000 \\
\hline Çek Cumhuriyeti & 0,8927 & 0,9088 & 0,9259 & 0,9483 & 1,0000 \\
\hline Danimarka & 0,9279 & 0,9401 & 0,9521 & 0,9662 & 0,9832 \\
\hline Estonya & 0,8992 & 0,9143 & 0,9305 & 0,9481 & 0,9678 \\
\hline Finlandiya & 0,8920 & 0,9035 & 0,9161 & 0,9408 & 0,9744 \\
\hline Fransa & 0,9642 & 0,9728 & 0,9820 & 0,9907 & 1,0000 \\
\hline Hollanda & 0,9106 & 0,9221 & 0,9362 & 0,9598 & 0,9995 \\
\hline İrlanda & 0,9443 & 0,9582 & 0,9719 & 0,9859 & 1,0000 \\
\hline İspanya & 0,9392 & 0,9543 & 0,9693 & 0,9846 & 1,0000 \\
\hline İsrail & 0,9638 & 0,9725 & 0,9818 & 0,9906 & 1,0000 \\
\hline İsvec & 0,9373 & 0,9524 & 0,9682 & 0,9837 & 1,0000 \\
\hline İsviçre & 0,9387 & 0,9537 & 0,9690 & 0,9844 & 1,0000 \\
\hline İtalya & 0,9605 & 0,9702 & 0,9802 & 0,9898 & 1,0000 \\
\hline İlanda & 0,9557 & 0,9667 & 0,9776 & 0,9889 & 1,0000 \\
\hline Japonya & 0,9658 & 0,9740 & 0,9827 & 0,9911 & 1,0000 \\
\hline Kanada & 0,9547 & 0,9657 & 0,9772 & 0,9885 & 1,0000 \\
\hline Kore & 0,9331 & 0,9495 & 0,9659 & 0,9830 & 1,0000 \\
\hline Lüksemburg & 0,9661 & 0,9742 & 0,9829 & 0,9912 & 1,0000 \\
\hline Macaristan & 0,8574 & 0,8732 & 0,8910 & 0,9279 & 1,0000 \\
\hline Meksika & 0,9609 & 0,9704 & 0,9803 & 0,9899 & 1,0000 \\
\hline Norveç & 0,9347 & 0,9458 & 0,9574 & 0,9688 & 0,9806 \\
\hline Polonya & 0,9032 & 0,9251 & 0,9491 & 0,9742 & 1,0000 \\
\hline Portekiz & 0,9075 & 0,9215 & 0,9367 & 0,9536 & 0,9705 \\
\hline Slovakya & 0,9068 & 0,9288 & 0,9519 & 0,9752 & 1,0000 \\
\hline Slovenya & 0,9120 & 0,9241 & 0,9364 & 0,9490 & 0,9685 \\
\hline Şili & 0,9608 & 0,9703 & 0,9801 & 0,9898 & 1,0000 \\
\hline Türkiye & 0,9184 & 0,9376 & 0,9579 & 0,9785 & 1,0000 \\
\hline Yeni Zelanda & 0,9534 & 0,9648 & 0,9763 & 0,9879 & 1,0000 \\
\hline Yunanistan & 0,8790 & 0,8969 & 0,9151 & 0,9340 & 0,9529 \\
\hline & & & & & \\
\hline
\end{tabular}

Alt sınır etkinlik değerlerine bakıldığında; $\alpha=0 ; 0,25 ; 0,50$ ve $0,75 \mathrm{kesim}$ düzeyinde hiçbir karar verme biriminin etkin olmadığı görülmektedir. Her dört $\alpha$ kesim düzeyinde de Macaristan (sırasıyla 0,$8574 ; 0,8732 ; 0,891 ; 0,9279$ ) en küçük alt sınır etkinlik değerine sahip ülkedir. $\alpha=0$ ve 0,25 kesim düzeyi için ikinci en küçük etkinlik değerine sahip ülke Yunanistan olurken; $\alpha=0,50$ ve 0,75 kesim düzeyi için ikinci en küçük etkinlik değerine sahip ülke Almanya'dır. Her dört $\alpha$ kesim düzeyinde de en büyük alt sınır değerine sahip ülkenin Avusturya (sırasıyla 0,9696; 0,9773; 0,9847; 0,9926) olduğu görülmektedir. Bunu her dört $\alpha$ kesim düzeyi için Lüksemburg takip etmektedir. $\alpha=1$ için belirlenen alt sınır etkinlik değerlerine bakıldığında ise ABD, Avustralya, Avusturya, Belçika, Birleşik Krallık, Çek Cumhuriyeti, Fransa, İrlanda, İspanya, İsrail, İsveç, İsviçre, İtalya, İzlanda, Japonya, Kanada, Kore, Lüksemburg, Macaristan, Meksika, Polonya, Slovakya, Şili, Türkiye ve Yeni 
Yeşilaydın, G. \& N. Alptekin (2016), "Bulanık Veri Zarflama Analizi İle OECD Ülkelerinin

Sağlık Alanındaki Etkinliklerinin Değerlendirilmesi”, Sosyoekonomi, Vol. 24(30), 207-224.

Zelanda'nın etkin ülkeler olduğu söylenebilir. Etkin olmayan ülkeler arasında ise $\alpha=1$ için en düşük alt sınır değerine sahip ülke Almanya $(0,9466)$ iken; en yüksek alt sınır değerine sahip ülke 0,9995 değeri ile Hollanda'dır (Tablo 2).

OECD ülkelerinin her $\alpha$ - kesim düzeyi için bulanık veri zarflama analizi kullanılarak elde edilen üst sınır etkinlik değerlerine ilişkin veriler ise Tablo 3 'de yer almaktadır.

Tablo: 3

Bulanık Veri Zarflama Analizi Çözümünde $\alpha$ - Kesim Düzeyleri İçin Üst Sınır Etkinlik Değerleri

\begin{tabular}{|c|c|c|c|c|c|}
\hline & \multicolumn{5}{|c|}{ ÜST SINIR ETKİNLIK DEĞERLERİ } \\
\hline & $\alpha=\mathbf{0}$ & $\alpha=\mathbf{0 , 2 5}$ & $\alpha=\mathbf{0 , 5 0}$ & $\alpha=0,75$ & $\alpha=1$ \\
\hline ABD & 1,0000 & 1,0000 & 1,0000 & 1,0000 & 1,0000 \\
\hline Almanya & 0,9454 & 0,9457 & 0,9460 & 0,9463 & 0,9466 \\
\hline Avustralya & 1,0000 & 1,0000 & 1,0000 & 1,0000 & 1,0000 \\
\hline Avusturya & 1,0000 & 1,0000 & 1,0000 & 1,0000 & 1,0000 \\
\hline Belçika & 1,0000 & 1,0000 & 1,0000 & 1,0000 & 1,0000 \\
\hline Birleșik Krallık & 1,0000 & 1,0000 & 1,0000 & 1,0000 & 1,0000 \\
\hline Çek Cumhuriyeti & 1,0000 & 1,0000 & 1,0000 & 1,0000 & 1,0000 \\
\hline Danimarka & 0,9834 & 0,9833 & 0,9833 & 0,9832 & 0,9832 \\
\hline Estonya & 0,9672 & 0,9673 & 0,9675 & 0,9676 & 0,9678 \\
\hline Finlandiya & 0,9740 & 0,9741 & 0,9742 & 0,9745 & 0,9744 \\
\hline Fransa & 1,0000 & 1,0000 & 1,0000 & 1,0000 & 1,0000 \\
\hline Hollanda & 1,0000 & 0,9995 & 0,9994 & 0,9992 & 0,9995 \\
\hline İrlanda & 1,0000 & 1,0000 & 1,0000 & 1,0000 & 1,0000 \\
\hline İspanya & 1,0000 & 1,0000 & 1,0000 & 1,0000 & 1,0000 \\
\hline İsrail & 1,0000 & 1,0000 & 1,0000 & 1,0000 & 1,0000 \\
\hline İsveç & 1,0000 & 1,0000 & 1,0000 & 1,0000 & 1,0000 \\
\hline İsviçre & 1,0000 & 1,0000 & 1,0000 & 1,0000 & 1,0000 \\
\hline İtalya & 1,0000 & 1,0000 & 1,0000 & 1,0000 & 1,0000 \\
\hline İzlanda & 1,0000 & 1,0000 & 1,0000 & 1,0000 & 1,0000 \\
\hline Japonya & 1,0000 & 1,0000 & 1,0000 & 1,0000 & 1,0000 \\
\hline Kanada & 1,0000 & 1,0000 & 1,0000 & 1,0000 & 1,0000 \\
\hline Kore & 1,0000 & 1,0000 & 1,0000 & 1,0000 & 1,0000 \\
\hline Lüksemburg & 1,0000 & 1,0000 & 1,0000 & 1,0000 & 1,0000 \\
\hline Macaristan & 1,0000 & 1,0000 & 1,0000 & 1,0000 & 1,0000 \\
\hline Meksika & 1,0000 & 1,0000 & 1,0000 & 1,0000 & 1,0000 \\
\hline Norveç & 0,9805 & 0,9805 & 0,9806 & 0,9806 & 0,9806 \\
\hline Polonya & 1,0000 & 1,0000 & 1,0000 & 1,0000 & 1,0000 \\
\hline Portekiz & 0,9702 & 0,9703 & 0,9704 & 0,9704 & 0,9705 \\
\hline Slovakya & 1,0000 & 1,0000 & 1,0000 & 1,0000 & 1,0000 \\
\hline Slovenya & 0,9675 & 0,9678 & 0,9680 & 0,9683 & 0,9685 \\
\hline Şili & 1,0000 & 1,0000 & 1,0000 & 1,0000 & 1,0000 \\
\hline Türkiye & 1,0000 & 1,0000 & 1,0000 & 1,0000 & 1,0000 \\
\hline Yeni Zelanda & 1,0000 & 1,0000 & 1,0000 & 1,0000 & 1,0000 \\
\hline Yunanistan & 0,9515 & 0,9519 & 0,9522 & 0,9526 & 0,9529 \\
\hline
\end{tabular}

Üst sınır etkinlik değerlerine bakıldığında ise beş $\alpha$ - kesim düzeyinde de ABD, Avustralya, Avusturya, Belçika, Birleşik Krallık, Çek Cumhuriyeti, Fransa, İrlanda, İspanya, İsrail, İsveç, İsviçre, İtalya, İzlanda, Japonya, Kanada, Kore, Lüksemburg, Macaristan, Meksika, Polonya, Slovakya, Şili, Türkiye ve Yeni Zelanda'nın etkin olduğu 
görülmektedir. Hollanda ise sadece $\alpha=0$ kesim düzeyinde etkindir. Etkin olmayan ülkelerden üst sınır etkinlik değeri en küçük olan ülke tüm $\alpha$ - kesim düzeylerinde Almanya iken; üst sınır etkinlik değeri en yüksek olan ülke $\alpha=0$ için Danimarka; $\alpha=0,25 ; 0,50$ ve 0,75 için ise Hollanda'dır (Tablo 3).

Tablo 2 ve Tablo 3 birlikte incelendiğinde, $\alpha=1$ için Almanya'nın hem alt sınır hem de üst sınır değerlerine göre en düşük etkinliğe; Hollanda'nın ise en yüksek etkinliğe sahip olduğu söylenebilir.

\subsection{Minimaks Pişmanlık Yaklaşımına İlişkin Bulgular}

Tüm $\alpha$ düzeylerine ilişkin maksimum etkinlik kaybı değerleri ve ülke sıralamaları Tablo 4 'te sunulmuştur.

$\alpha=0 ; 0,25 ; 0,50$ ve 0,75 kesim düzeyinde en iyi etkinlik kaybı değerini alan ilk beş ülke sırasıyla Avusturya, Lüksemburg, Japonya, Fransa ve İsrail'dir. Bahsi geçen dört $\alpha$ kesim düzeyi için de en kötü etkinlik kaybı değeri Macaristan'a aittir. $\alpha=1$ kesim düzeyine bakıldı̆̆ında; Hollanda, Danimarka, Norveç, Finlandiya, Portekiz, Slovenya, Estonya, Yunanistan ve Almanya dişındaki diğer ülkelerin etkin olduğu; bu nedenle Tablo 4'te yer almadığı görülmektedir. $\alpha=1$ kesim düzeyinde etkin olmayan ülkelerden Hollanda, en iyi etkinlik kaybı değerine sahip ülkedir. En kötü etkinlik kaybı değerine sahip olan ülke ise Almanya'dır. Türkiye ise $\alpha=0 ; 0,25 ; 0,50$ ve 0,75 kesim düzeyi için 34 ülke içerisinde orta siralarda (21. ve 23. sira) yer almakta; $\alpha=1$ kesim düzeyinde ise etkin ülkeler arasında bulunmaktadır (Tablo 4). 
Tablo: 4

Maksimum Etkinlik Kaybı Değerleri ve Ülke Sıralamaları

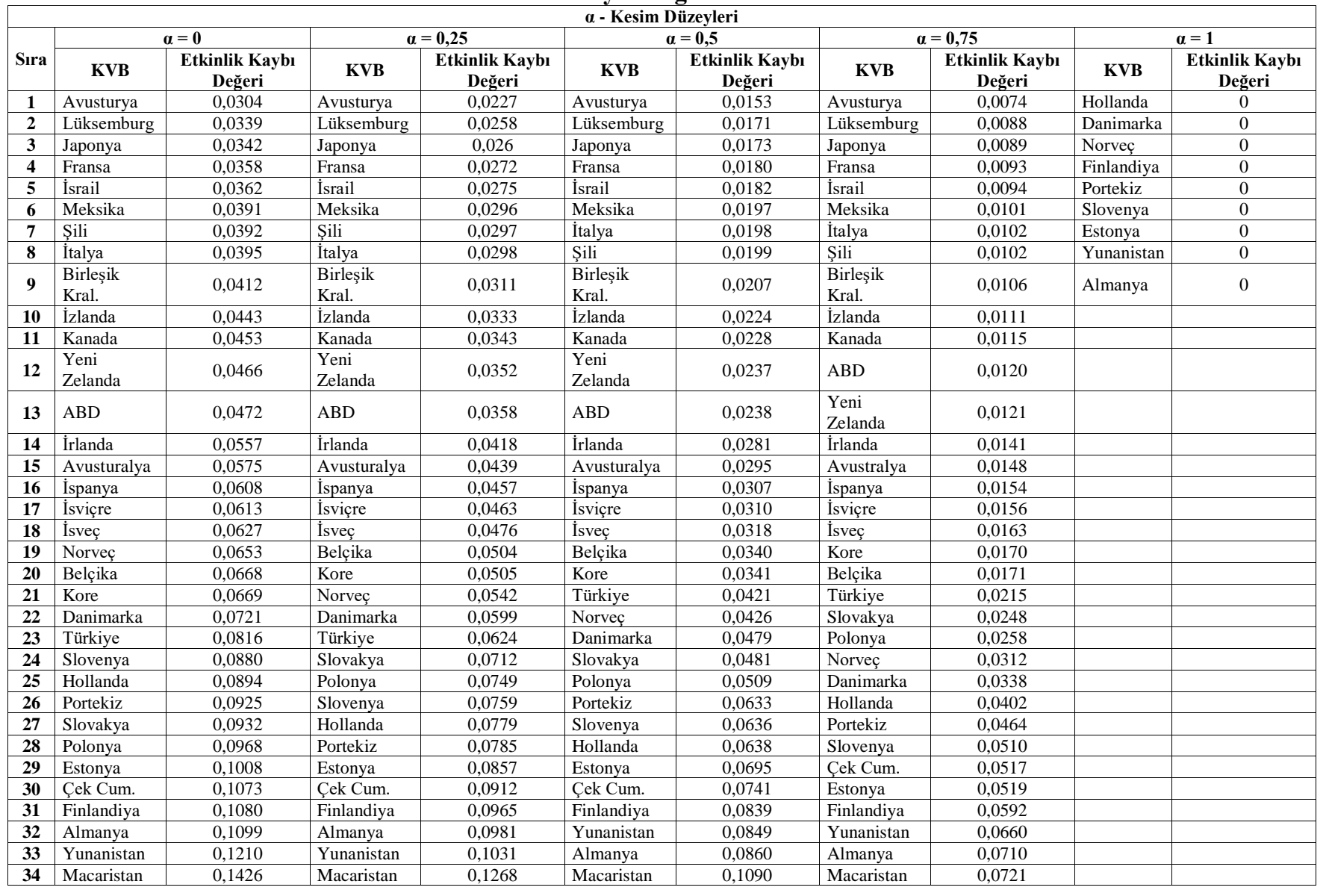


Yeşilaydın, G. \& N. Alptekin (2016), "Bulanık Veri Zarflama Analizi İle OECD Ülkelerinin

Sağlık Alanındaki Etkinliklerinin Değerlendirilmesi”, Sosyoekonomi, Vol. 24(30), 207-224.

\section{Sonuç ve Öneriler}

Sağlık; sosyal ve kültürel hayat, ekonomi, politika, teknoloji ve eğitim gibi birçok alanla etkileşim halinde olan açık bir sistemdir. $\mathrm{Bu}$ nedenle sağlık hizmeti sunumunda sağlığı tek başına ele almak, yalnızca sağlık ile ilgili değişkenlere yer vermek yanıltıcı olabilmektedir. Bu düşünceden yola çıkılarak bu çalışmada, ülkelerin sağlık etkinliklerinin belirlenmesinde sağlık ile doğrudan ilişkili değişkenlerin yanı sıra çevre değişkenlerine (dışsal değişkenler) de yer verilmiştir.

Bulanık veri zarflama analizinde kullanılan değişkenler; 1000 kişiye düşen hekim sayısı, 1000 kişiye düşen hastane yatağı sayısı, satın alma gücü paritesine göre Amerikan Doları cinsinden kişi başı sağlık harcamaları olmak üzere üç girdi; günlük sigara içen 15 yaş üstü erişkinlerin yüzdesi, meyve tüketimi (yılda kişi başına $\mathrm{kg}$ ), kızamık aşısı olan çocukların yüzdesi, karbonmonoksit emisyonu (kişi başı kg), 5-39 yaş arası beklenen okullaşma (eğitim) yılı olmak üzere beş çevre; doğumda beklenen yaşam süresi ve anne ölüm hızı olmak üzere iki çıktı değişkeninden oluşmaktadır. Çevre değişkenleri de birer girdi değişkeni olarak ele alındığından, çalışmada toplam sekiz girdi ve iki çıktı değişkeni bulunmaktadır.

Bulanık veri zarflama analizi ile ilgili geliştirilmiş çok sayıda model bulunmaktadır. $\mathrm{Bu}$ çalışmada Wang, Greatbanks ve Yang (2005) modeli kullanılmıştır. Bu modelin kullanılmak üzere seçilmesinin nedeni ise literatürde çok sayıda makale ve tez çalışmasında sıklıkla kullanılmış olmasıdır. Bu model; aralık veriler ve $\alpha$ - kesim kümesi yaklaşımına dayanan alt ve üst sınır etkinliğine ilişkin matematiksel modellerin oluşturulması ve bu modellerin çözümleri esasına dayanır. Çalışmada $\alpha=0 ; 0,25 ; 0,50 ; 0,75$ ve 1 olmak üzere beş farklı $\alpha$-kesim düzeyinde işlem yapılmıştır. Her bir karar verme birimine iliş̧kin etkinliklerin bulunmasının ardından literatürde sıklıkla kullanılan "Minimaks Pişmanlık Yaklaşımı" yöntemi ile ülkeler, alt ve üst sınır etkinlik değerlerine göre sıralanmışlardır.

Minimaks Pişmanlık Yaklaşımı ile elde edilen sonuçlara göre; $\alpha=0 ; 0,25 ; 0,50$ ve 0,75 kesim düzeyinde en iyi etkinlik kaybı değerini alan ilk beş ülke sırasıyla Avusturya, Lüksemburg, Japonya, Fransa ve İsrail'dir. Bahsi geçen dört $\alpha$ kesim düzeyi için de en kötü etkinlik kaybı değeri Macaristan'a aittir. $\alpha=1$ kesim düzeyine bakıldığında; Hollanda, Danimarka, Norveç, Finlandiya, Portekiz, Slovenya, Estonya, Yunanistan ve Almanya dışındaki diğer ülkelerin etkin olduğu görülmektedir. $\alpha=1$ kesim düzeyinde etkin olmayan ülkelerden Hollanda, en iyi etkinlik kaybı değerine sahip ülkedir. En kötü etkinlik kaybı değerine sahip olan ülke ise Almanya'dır. Türkiye ise $\alpha=0 ; 0,25 ; 0,50$ ve 0,75 kesim düzeyi için 34 ülke içerisinde orta sıralarda (21. ve 23. sıra) yer almakta; $\alpha=1$ kesim düzeyinde ise etkin ülkeler arasında bulunmaktadır.

OECD ülkeleri arasında Türkiye'nin belirlenen değişkenler bakımından mevcut durumunun tespiti amacıyla 34 ülke ile Türkiye'nin verileri karşılaştırılmıştır. Buna göre, Türkiye, 34 ülke içinde 1000 kişiye düşen hekim sayısı en az olan ikinci; 1000 kişiye düşen hastane yatağ1 sayısı en az olan dördüncü; satın alma gücü paritesi (US\$)'ne göre kişi baş1 sağlık harcaması en az olan birinci; 5-39 yaş arası beklenen okullaşma (eğitim) yılı en düşük 
Yeşilaydın, G. \& N. Alptekin (2016), "Bulanık Veri Zarflama Analizi İle OECD Ülkelerinin

Sağlık Alanındaki Etkinliklerinin Değerlendirilmesi”, Sosyoekonomi, Vol. 24(30), 207-224.

yedinci ve doğumda beklenen yaşam süresi en düşük ikinci; anne ölüm hızı ise en yüksek dördüncü ülkedir. Ancak günlük sigara içen 15 yaş üstü erişkinlerin yüzdesi, meyve tüketimi, kızamık aşısı olan çocukların yüzdesi ve $\mathrm{CO}_{2}$ emisyonu değişkenleri bakımından orta siralarda yer almaktadir.

Türkiye'nin bazı değişkenler açısından orta düzeyde bir etkinlik göstermesine rağmen; daha iyi sağlık düzeyine erişebilmesi için özellikle hekim sayısı, hastane yatağı sayısı, kişi başı sağlık harcamaları, 5-39 yaş arası beklenen okullaşma (eğitim) yılı ve doğumda beklenen yaşam süresi değişkenleri bakımından daha yüksek değerlere ulaşması, ekonomik istikrarın sağlanması ve toplumun eğitim ve bilinç düzeyinin yükseltilmesi gerektiği düşünülmektedir.

Bu çalışmanın sağlık alanında ülkeler arası karşılaştırmalar yapılması ve Türkiye'nin ait olduğu kümedeki diğer ülkelere göre mevcut durumunun değerlendirilmesi açısından sağlık yöneticilerine, planlamacılara, politika yapıcılara, karar vericilere ve konu ile ilgilenen akademisyenlere yardımcı olması arzu edilmektedir. Çalışma kapsamında yapılan karşılaştırmalar ile ülkelerin özellikle de Türkiye'nin ekonomik hedefleri ve reform hareketlerine yönelik farklı bir bakış açısı sağlanması, sağlık sistemine ilişkin etkinlik ya da etkinsizlik düzeylerinin belirlenmesi, sağlık alanındaki etkinliği yüksek olan ülkelerin model alınması ve bu ülkelerin Türkiye için yol gösterici olması hedeflenmektedir.

Ülkelerin sağlık düzeylerinin belirlenmesi ile ilgili bundan sonra yapılacak çalışmalarda sağlığı doğrudan ya da dolaylı olarak etkileyen değişkenlerin sayılarının artırılmasının ve farklı çevre değişkenlerinin ele alınmasının faydalı olacağı düşünülmektedir.

\section{Kaynaklar}

Afsharinia, A. \& M. Bagherpour \& K. Farahmand (2013), "Efficiency Measurement of Clinical Units Using Integrated Independent Component Analysis - DEA Model Under Fuzzy Conditions", International Journal of Hospital Research, 2(3), 108-117.

Altıntaş, T. (2012), “Türkiye ve Avrupa Birliği’ne Üye Ülkelerin Sağlık Göstergeleri Açısından Çok Değişkenli İstatistik Yöntemlerle Karşılaştırılması”, Doktora Tezi, İstanbul Üniversitesi Sosyal Bilimler Enstitüsü, İstanbul.

Apaydın, A. \& T. Güneş (2007), "Bulanık Veri Zarflama Analizi Tekniği ile Türkiye'de Birinci Derece Kalkınma Öncelikli Yörelerin Etkinliklerinin Ölçülmesi”, 5. İstatistik Kongresi. Antalya, 134-135.

Artut, A. (2013), “İktisadi ve İdari Bilimler Fakültelerinin Bulanık Veri Zarflama Analizi ile Etkinlik Ölçümü”, Yüksek Lisans Tezi, Cumhuriyet Üniversitesi Sosyal Bilimler Enstitüsü, Sivas.

Auster, R. \& I. Leveson \& D. Sarachek (1972), “The Production of Health, an Exploratory Study”, V.R.Fuchs (Ed.), Essays in the Economics of Health and Medical Care içinde, New York: National Bureau of Economic Research, 135-158, <http://www.nber.org/chapters/c3454>, 14.10.2015.

Balkan, H. (2011), "Determining the Relative Efficiency of the Shock Markets by Classical and Fuzzy Data Envelopment Analysis", Yüksek Lisans Tezi, Bahçeşehir Üniversitesi Fen Bilimleri Enstitüsü, İstanbul. 
Yeşilaydın, G. \& N. Alptekin (2016), "Bulanık Veri Zarflama Analizi İle OECD Ülkelerinin Sağlık Alanındaki Etkinliklerinin Değerlendirilmesi”, Sosyoekonomi, Vol. 24(30), 207-224.

Costantino, N. \& M. Dotoli \& N. Epicoco \& M. Falagario \& F. Sciancalepore (2013), "Using CrossEfficiency Fuzzy Data Envelopment Analysis For Healthcare Facilities Performance Evaluation Under Uncertainty", International Conference on Systems, Man, and Cybernetics, Manchester, 912-917.

Çakır, S. (2015), "Bütünleşik Bulanık Shannon Entropi-Bulanık Veri Zarflama Analizi Yöntemiyle Teknoloji Firmalarında Etkinlik Ölçümü”, Doktora Tezi, Karadeniz Teknik Üniversitesi Sosyal Bilimler Enstitüsü, Trabzon.

Demir, A. \& F. Bakırcı (2014), "OECD Üyesi Ülkelerin Ekonomik Etkinliklerinin Veri Zarflama Analiziyle Ölçümü”, Atatürk Üniversitesi İktisadi ve İdari Bilimler Dergisi, 28(2), 109132.

Ebrahimnejad, A. (2012), “Cost Efficiency Measures With Trapezoidal Fuzzy Numbers in Data Envelopment Analysis Based on Ranking Functions: Application in Insurance Organization and Hospital”, International Journal of Fuzzy System Applications, 2(3), 51-68.

Ege, İ. (2009), "Firmaların Etkinliğinin Bulanık Veri Zarflama Analizi ile Belirlenmesi: İMKB 30 Endeksi Üzerine Bir Uygulama”, EconAnadolu 2009: Anadolu Uluslararası İktisat Kongresi, Eskişehir.

Güneş, T. (2006), "Bulanık Veri Zarflama Analizi”, Yüksek Lisans Tezi, Ankara Üniversitesi Fen Bilimleri Enstitüsü, Ankara.

Güngör, İ. \& K.O. Oruç (2009), "Bulanık Veri Zarflama Analizi Modellerinin Karşılaştırılması: Sıralı ve Sınırlandırılmış Bulanık Veriler İçin”, Alanya İşletme Fakültesi Dergisi, 1(1), 17-32.

Hadi-Vencheh, A. \& A. Hatami-Marbini \& Z. Ghelej Beigi \& K. Gholami (2014), “An Inverse Optimization Model for Imprecise Data Envelopment Analysis”, Optimization, (aheadof-print), 1-14.

Hatami-Marbini, A. (2011), "Data Envelopment Analysis with Fuzzy Parameters: an Interactive Approach", International Journal of Operations Research and Information Systems, 2(3), 39-53.

Hatami-Marbini, A. \& A. Emrouznejad \& M. Tavana (2011), “A Taxonomy and Review of the Fuzzy Data Envelopment Analysis Literature: Two Decades in the Making”, European Journal of Operational Research, 214, 457-472.

Kocaman, A.M. \& M. Mutlu \& D. Bayraktar \& Ö.M. Araz (2012), “OECD Ülkelerinin Sağl1k Sistemlerinin Etkinlik Analizi”, Endüstri Mühendisliği Dergisi, 23(4), 14-31.

Kumar, A. \& L. Özdamar (2004), "International Comparison of Healthcare Systems”, International Journal of the Computer, the Internet and Management, 12(3), 81-95.

Lertworasirikul, S. \& S.C. Fang \& J.A. Joines \& H.L.W. Nuttle (2003), "Fuzzy Data Envelopment Analysis (DEA): A Possibility Approach”, Fuzzy Sets and Systems, 139, 379-394.

Lorcu, F. (2008), "Veri Zarflama Analizi (DEA) ile Türkiye ve Avrupa Birliği Ülkelerinin Sağlık Alanındaki Etkinliklerinin Değerlendirilmesi”, Doktora Tezi, İstanbul Üniversitesi Sosyal Bilimler Enstitüsü, İstanbul.

Lorcu, F. \& B. Acar Bolat \& A. Atakişi (2012), "Examining Turkey and Member States of European Union in Terms of Health Perspectives of Millennium Development Goals", Quality and Quantity, 46, 959-978. 
Orhan Aksoy, S. (2007), “Türkiye'de Yerleşim Yeri Bazlı Sağlık Belirleyicilerinin Bazı Sağlık Düzeyi Göstergeleri ile İlişkisi, Yüksek Lisans Tezi, Celal Bayar Üniversitesi Sağlık Bilimleri Enstitüsü, Manisa.

Oruç, K.O. \& İ. Güngör \& M.F. Demiral (2009), “Üniversitelerin Etkinlik Ölçümünde Bulanık Veri Zarflama Analizi Uygulaması”, Selçuk Üniversitesi Sosyal Bilimler Enstitüsü Dergisi, 22, 279-294.

Razavi, S.H. \& H. Amoozad \& E.K. Zavadskas \& S.S. Hashemi (2013), “A Fuzzy Data Envelopment Analysis Approach Based on Parametric Programming", International Journal of Computers Communications and Control, 8(4), 594-607.

Retzlaff-Roberts, D. \& C.F. Chang \& R.M. Rubin (2004), "Technical Efficiency in the Use of Healthcare Resources: A Comparison of OECD Countries”, Health Policy, 69(1), 55-72.

Saen, R.F. (2011), “An Innovative Approach for International Market Selection”, International Conference on Computer Communication and Management, Singapore, 598-601.

Sağlık Bakanlığı Temel Sağlık Hizmetleri Genel Müdürlüğü (2011), Să̆llğın Teşviki ve Geliştirilmesi Sözlüğ̈̈, Ankara.

Sümbüloğlu, V. \& R.E. Sezer \& K. Sümbüloğlu (1999), “Epidemiyoloji ve Araştırma Teknikleri”, Somgür Yayıncılık, Ankara.

Şafak, İ. (2009), “Ege Bölgesi Orman İşletmelerinin Etkinlik Düzeylerinin Belirlenmesi”, Doktora Tezi, Celal Bayar Üniversitesi Sosyal Bilimler Enstitüsü, Manisa.

Şafak, İ. \& A.U. Gül \& M.E. Akkaş \& S.Ü. Portakal \& M. Gediklili \& Ş.M. Kanat (2013), "Efficiency Determination of the Forest Sub-Districts By Using Fuzzy Data Envelopment Analysis (Case Study: İzmir Forest Regional Directorate)", Eurasian Journal of Forest Science, 1(1), 1-19.

Tarcan, M. \& Y. Çelik \& C. Plante \& M. Younis (2015), “An Investigation into the Economies of Scale in Turkish Ministry of Health Hospitals", Journal of Public Budgeting, Accounting and Financial Management, 27(1), 98-116.

Temür, Y. \& F. Bakırcı (2008), “Türkiye'de Sağlık Kurumlarının Performans Analizi: Bir VZA Uygulamas1”, Sosyal Bilimler Dergisi, X(3), 261-281.

Ünal, E. (2012), “Sağlık Ekonomisi”, M. Ateş (Ed.), Sağlık İşletmeciliği, Beta Yayınları, İstanbul, 179-235.

Wang, Y.M. \& R. Greatbanks \& J.B. Yang (2005a), "Interval Efficiency Assessment Using Data Envelopment Analysis", Fuzzy Sets and Systems, 153, 347-370.

Wang, Y.M. \& J.B. Yang \& D.L. Xu (2005b), “A Preference Aggregation Method through the Estimation of Utility Intervals", Computers and Operations Research, 32, 2027-2049.

WHO (2014), Global Reference List of 100 Core Health Indicators, Geneva.

Vehid, S. (2000), “Temel Demografik ve Sağlık Düzeyi Ölçütleri Açısından Türkiye ile Avrupa Birliği’ne (AB) Üye Ülkelerin Karşılaştırılması”, Cerrahpaşa Tıp Dergisi, 31(2), 100106. 
Yeşilaydın, G. \& N. Alptekin (2016), "Bulanık Veri Zarflama Analizi İle OECD Ülkelerinin Sağlık Alanındaki Etkinliklerinin Değerlendirilmesi”, Sosyoekonomi, Vol. 24(30), 207-224. 